Euskal ikerketen aldizkaria | Revue d'études basques |

Revista de estudios vascos | Basque studies review

$3 \mid 1998$

Numéro III

\title{
Jan Braun. Euscaro-Caucasica.
}

Philologia Orientalis 4 Wydawnictwo Akademickie DIALCX3, Warszawa, 1998, 148.orr.

\section{Txomin Peillen}

\section{(2) OpenEdition}

\section{Journals}

Édition électronique

URL : https://journals.openedition.org/lapurdum/1742

DOI : 10.4000/lapurdum. 1742

ISSN : 1965-0655

\section{Éditeur}

IKER

\section{Édition imprimée}

Date de publication : 1 octobre 1998

Pagination : 313-315

ISBN : 2-84127-152-8

ISSN : $1273-3830$

Référence électronique

Txomin Peillen, « Jan Braun. Euscaro-Caucasica. », Lapurdum [En ligne], 3 | 1998, mis en ligne le 01 septembre 2010, consulté le 25 février 2022. URL : http://journals.openedition.org/lapurdum/1742 ; DOI : https://doi.org/10.4000/lapurdum.1742 


\section{JAN BRAUN. EUSCARO-CAUCASICA.}

Philologia Orientalis 4 Wydawnictwo Akademickie DIALOG, Warszawa, 1998, 148.orr.

Varsoviako unibertsitari eta euskalari honek bere konparaketa lan hau eman digu. Urrungo hizkuntzekin euskararen hurbiltzeak arrisku haundiak ditu, baina holako liburu batek orokorki zerbait ekar lezake, batikbat tipologiazko sailkapenak zorrozłuz. Honek ez du erran nahi hurbil mintzairen artean harreman zuzenik izan denik, ez telepatiarik, baina egia da aglutinazioa hautatu duten herriek maiz aterabide berdinak ediren dituztela. Morfologiaren sailean gauza jakingarriak ematen ditu eta gramatikan ere besterik badago, hitzekin, ordea, hurbilketa zailagoa da, denborarekin hiztegia ainitz alda baititake eta auzo mintzairetikako maileguak ezpaititugu osoki bereizi.

Egileak erdarak hobeki baitakizki euskara baino aipamen hau frantsesez jarraituko dut, egileak berak gaztelania, ingelesa eta errusieraz idatzi baitu bere liburua.

L'auteur reprend les correspondances phonétiques de René Lafon mais plus que les ressemblances lexicales qui sont toujours discutables et qui peuvent se faire avec n'importe qu'elle langue; discutables aussi parce que après des milliers d'années de séparation éventuelle - si contact il y a eu - les vocabulaires deviennent méconnaissables.

Certes il est très intéressant de noter que le vocabulaire géorgien se présente systématiquement terminé par le $-i$ du nominatif et que le $-i$ est en basque caractéristique du verbe au passif ancien likusi "voir " ekarri "apporter " ikasi " apprendre ", irakurri "lire ", des adjectifs handi " grand ", txipi " petit ", lodi " gros " et des noms de la couche la plus ancienne de la langue, begi « œil », beharri « oreille ", ardi « brebis", behi « vache ", idi « boeuf ").

Quant au lexique, partie la plus changeante et la plus labile de toute langue, son étude exigerait que nous ayons au préalable dégagé notre lexique des emprunts aux parlers indo-européens voisins, ce qui est loin d'être fait; bien des termes pouvant être de simples prêts du latin ou de langues romanes. Voyons quelques rapprochements :

1.ztzz (géorgien) rapproché de atze(?) " arbre en basque ". Dans notre langue existe le terme zuhaitz(e)/zugaitz littéralement zurgaitz " bois dressé " (cf uhaitz/gaitz « torrent ") mais pas atze. "Par contre -tze/-tza est un suffixe basque en botanique. Existet-il en géorgien ancien?

2. Zir-i (georg) « racine », ziri (basq) « coin » (p.54) rapprochement intéressant, ziri signifie aussi « verge humaine".

Plus intéressants sont : 


\begin{tabular}{|c|c|c|}
\hline \multirow[t]{2}{*}{ géorgien } & \multicolumn{2}{|l|}{ basque } \\
\hline & & sin \\
\hline ze « étendre " & $-t z a$ & etzan "s'étendre " \\
\hline zar " bouger" & tzal,tzur & itzuri « fuir» \\
\hline zen « lait» & -zen & $\begin{array}{l}\text { zenbera "fromage frais" } \\
\text { esne/ezne: " lait " }\end{array}$ \\
\hline $\mathrm{c} / \mathrm{tz}$ cval (tzval) & $-t z u l$ & itzuli « retourner " \\
\hline tqorc " jeter" & ortz & $\begin{array}{l}\text { ehortzi \& enterrer" } \\
\text { egoitzi « abattre " }\end{array}$ \\
\hline kas \& effacer » & $-k u z$ & ikuzi « laver » \\
\hline \multicolumn{3}{|l|}{$\mathrm{c} / \mathrm{ts}, \mathrm{s}$} \\
\hline marcqv (p.48) & & martsuka " mûre » \\
\hline çam/al/i « foin» & $\mathrm{zamar} / \mathrm{tc}$ & be sèche $n$ \\
\hline
\end{tabular}

Les autres termes supposent des contorsions de sens et de formes qui, il est vrai, s'observent entre les dialectes basques, mais ce qui est le plus gênant c'est que les mots choisis sont parfois isolés dans la langue ou bien appartiennent à une famille qu'il foudrait comparer entièrement.

11. Tagu est comparé au basque sagu, mais ce terme est un élément de la famille de satitsu " musaraigne "sator * taupe "sagarroi « hérisson " etc.

Le tama cf. zamar « tignasse, poil » (p. 13.2) est le même que çamli " herbes sèches en touffe » en basque zamar « herbe dure ». (p.12. 4.) La métaphore agricole est passée à la coiffure. En français aussi, les poils rèches, les tignasses raides sont qualifiés de « bottes de foin » et les poils durs isolés d'« épi ».

*Tapali a miel » (p. 14) est comparé à un sens secondaire de sapar « déchet de cire $»$; en effet sapar désigne tout déchet y compris les chassies des yeux et même localement les ronces.

Kantan « cime " comparé à kantal « roc » (p.75) fait oublier que le terme basque est un emprunt à l'espagnol (cf. canto, canton). II est curieux que koçol " petit " (p.88) n'ait pas été rapproché de koskor * petit, trognon " d'origine hispanolatine.

Kincxi (mingr.) (p.86) " cou " n'a rien à voir avec zintzur (et non zintzurri) " gorge $*$, ce dernier est une métaphore classique de la « noix " intzaur. 
II faut être prudent avec le gara-kara, basque (kwal, géorgien) attesté dans Kalagurri, ce radical est un mot ubiquiste pré-indoeuropéen qui évolua en basque en harri " pierre "d'une part et garai « hauteur " d'autre part, mais répandu dans toute l'Europe.

Le choix des mots, même si ce sont des hapax (khabar utilisé seulement à Ainhoa, L, kedar " bile ".l, est fait cependant dans le fond de la langue basque qui paraît le plus indigène mais gadurri « stream " p. 98 est un emprunt au gas-

con et p.64 en souletin c'est un " écoulement du corps " et non "fuente "qui se dit üthürri ; patar / pantar (p. 67) est le français " pentard " et pantika (p. 75) " rate " est le romanisme mantica. * Butur (p.59) n'existe pas en basque, mais musfur abréviation de musut tur, oui.

Le livre comporte des milliers de mots que nous ne pouvons reprendre un à un, mais il faut rappeler que Monsieur le Professeur Jan Braun, depuis 1954, a écrit en plus de ce livre une douzaine d'articles sur le basque en polonais, en anglais, en français, en espagnol, en russe et bien sûr en géorgien.

\section{Txomin PEILLeN}

Professeur émérite

Université de Pau et des Pays de l'Adour. 